\title{
EL IMPERIO DE LA MIRADA: "PTOSIS" DE GUADALUPE NETTEL
}

\author{
Jazmín G. Tapia Vázquez \\ El Colegio de México \\ jgtapia81@gmail.com
}

RESUMEN: En este artículo me propongo demostrar cómo la implicación del cuerpo enfermo proyecta uno de los principios artísticos que rigen la escritura de Guadalupe Nettel: el revelamiento de la anormalidad como una categoría estética. Para efecto de mi análisis, me centraré en el cuento "Ptosis" porque considero que la búsqueda del narrador y las reflexiones que subyacen en el texto sobre la fotografía perfilan la sensibilidad artística de la autora.

PALABRAS CLAVE: literatura mexicana, Guadalupe Nettel, cuerpo anómalo, fotografía

\begin{abstract}
In this article I have the goal of demonstrating how the implication of the sick body projects one of the artistic principals that governs Guadalupe Nettel's writing: the revealing of abnormality as an aesthetic category. For a deeper analysis, I will focus on the short story "Ptosis" since I consider that the search of a narrator and the reflections that underlie in the text about photography, outline the author's own artistic sensibility.
\end{abstract}

KEYWORDS: Mexican literature, Guadalupe Nettel, abnormal body, photography

Una de las motivaciones que impulsó la escritura del libro de cuentos Pétalos y otras historias incómodas (2006), tercer libro de cuentos de Guadalupe Nettel, fue dar a conocer, en palabras de la autora, que "las cosas que nos asustan y no queremos asumir [...] son la clave de nuestra verdadera belleza" (Friera, 2008). Con esta intención, Guadalupe Nettel construye "historias incómodas" de personajes que se regodean en sus obsesiones y diferencias, condenados a la incomunicación y a la soledad. Los personajes que aparecen en los cuentos de Pétalos son individuos inmersos en una rutina provocada por sus manías y obsesiones; por ejemplo, el narrador de "Pétalos", quien se dedica a recolectar olores que las mujeres desprenden en los baños públicos, o la protagonista de "Bezoar", quien en ataques compulsivos se desprende minuciosamente los cabellos con una pinza para después tragárselos. Las características que definen a los personajes nettelianos involucran, por un lado, la anomalía corporal, por otro, las patologías mentales, como las manías y las obsesiones. Estos rasgos los convierten en personajeslímite, entendidos como aquellos que están fuera de la norma, en los umbrales de la normalidad, ya sea por un trastorno corporal o mental que les impide una expresión coherente de su individualidad en el medio en el que se desenvuelven. Dentro de este catálogo de "gestos", como 
la autora prefiere nombrar a estos rasgos que caracterizan a sus personajes, me interesa destacar los que articulan el discurso en "Ptosis": la mirada obsesiva y los ojos anómalos por lo que revelan sobre la propuesta estética de Guadalupe Nettel.

En "Ptosis" se narra la historia de un hombre que trabaja como fotógrafo para un médico especializado en cirugías de párpados caídos. Su función consiste en tomar una serie de fotografías a los pacientes para constatar el estado de sus párpados antes y después de la cirugía correctiva de esta "anomalía". El narrador desarrolla un profundo interés por esa alteración corporal porque considera que en él radica la belleza y la singularidad de los pacientes. Ese interés se convierte pronto en una obsesión que lo impulsa a buscar, en las calles de París, párpados insólitos.

La búsqueda desesperada del narrador por capturar ese "gesto" que particulariza la corporeidad de los sujetos está estrechamente relacionada con la concepción de Guadalupe Nettel sobre el arte y los efectos que este produce. Para la autora, "la belleza en el arte la reconocemos en eso que es irrepetible, que incomoda, que nos toca afectiva o estéticamente" (Friera, 2008). De acuerdo con esta declaración, me propongo demostrar cómo la implicación del cuerpo enfermo proyecta uno de los principios artísticos que rigen la escritura de Guadalupe Nettel: el revelamiento de la anomalía como una categoría estética. Para efecto de mi análisis, me centraré en el cuento "Ptosis" porque considero que la búsqueda del narrador y las reflexiones que subyacen en el texto sobre la fotografía perfilan la sensibilidad artística de la autora.

\section{El cuerpo anómalo como objeto estético}

En la obra de Guadalupe Nettel, el cuerpo tiene una presencia cardinal que define, en buena medida, el rasgo distintivo de su escritura. Sin embargo, el cuerpo no solo es un reducto temático para sus obsesiones, sino que concentra la función del objeto estético porque opera como medio para reformular y representar la realidad desde otra perspectiva. Por lo tanto, el objeto estético promueve, en primer lugar, el cuestionamiento sobre la manera en la que naturalmente observamos la realidad, y en segundo, la creación de otra forma de percibirla. En ese sentido, el cuerpo que se codifica en la escritura de Nettel funcionará como un mecanismo textual que articula un modo de "mirar" y, por lo tanto, de comprender el mundo, en este caso, filtrado por la anomalía.

El título del cuento ${ }^{1}$ remite al ámbito corporal signado por una deformación, una alteración de lo armónico, natural y normal que caracteriza un cuerpo sano. El cuento codifica el cuerpo desde una anomalía en la que se revela su diferencia y le confiere singularidad porque, de acuerdo con Bacarlett, "la anomalía se refiere siempre a una diferencia, a una deformación, que se despliega espacialmente en la superficie del cuerpo o en la forma de los órganos, y que sólo puede determinarse relacionalmente, comparativamente. [...] la anomalía [es] la diferencia

\footnotetext{
${ }^{1}$ La palabra ptosis, en griego "caída", designa una condición médica que consiste en el descenso del párpado, ocasionado por una circunstancia genética, una lesión severa o por el proceso natural de envejecimiento. Esta condición es reversible mediante un proceso quirúrgico al que recurren, generalmente, las personas que buscan mejorar estéticamente el aspecto de sus ojos.
} 
radical morfológica entre dos cuerpos u órganos que nos impide reducir uno a otro" (2010: 165). Es decir, el cuerpo anómalo, entendido como una desviación de la norma, solo puede ser asimilado como tal cuando es comparado con un cuerpo normal, "armónico"; sin embargo, su categoría como lo diferente, lo singular y lo bello no es inherente al cuerpo anómalo, sino que está dada por quien lo ve. ${ }^{2}$

Guadalupe Nettel sostiene que lo bello "está en lo que nos hace únicos” (Marcos, 2013), en aquel rasgo diferenciador que es "irrepetible, que incomoda, que nos toca afectiva o estéticamente" (Friera, 2008). Estas declaraciones apuntan a la configuración del objeto que es centro de su propuesta estética y a la sensibilidad artística con la que se le acerca. Si lo bello habita en los cuerpos contrariados por una anomalía, la búsqueda artística de la autora se desplaza a esas "zonas" ocultas que la gente "prefiere no mirar" con la intención de visibilizar aquello que la "toca" afectiva y estéticamente porque, como apunta Kant, "las diferentes sensaciones de contento o disgusto descansan, no tanto sobre la condición de las cosas externas que las suscitan, como sobre la sensibilidad peculiar a cada hombre para ser grata e ingratamente impresionado por ellas" (Kant, 2003: 2), es decir, el valor estético de un objeto solo depende de la sensibilidad de la mirada que lo contempla. De ahí la importancia que "Ptosis" confiere a la mirada, acentuada por el ojo mecánico de la cámara fotográfica, como medio para capturar la belleza del cuerpo anómalo.

La configuración de la mirada obsesiva del narrador proyecta el posicionamiento de la autora desde donde filtra la realidad para desarticular los valores que se otorgan al cuerpo sano en la sociedad contemporánea, en la medida en la que visibiliza la anomalía como otra posibilidad de la realidad y le confiere un valor estético, de la misma manera que lo hace el protagonista del cuento. De esta forma, "Ptosis" funciona como un espacio de condensación de la poética de Guadalupe Nettel, ya que promueve un ejercicio reflexivo sobre el hacer artístico. En estas reflexiones se involucra, como se verá, el cuestionamiento sobre la relación entre objeto estético y realidad, la utilidad del arte y el valor de lo bello.

En contraposición al ámbito orgánico que sugiere el título, el cuento inicia con la descripción del narrador sobre el oficio mecánico de su progenitor:

El trabajo de mi padre, como muchos en esta ciudad, es un empleo parasitario. Fotógrafo de profesión, se habría muerto de hambre - y con él toda la familia - de no haber sido por la propuesta generosa del doctor Ruellan, que, además de un salario decente, le otorgó a su impredecible inspiración la posibilidad de concentrarse en una tarea mecánica sin mayores complicaciones. (Nettel, 2008:13)

Que el ímpetu artístico del padre se atempere en una tarea mecanizada al servicio de la ciencia delinea una reflexión sobre el estatuto estético de la fotografía que encuentra resonancias en los

\footnotetext{
${ }^{2}$ Empleo el verbo ver porque, de acuerdo con Bacarlett, la enfermedad se destaca por su visibilidad, es decir, puede verse y, por lo tanto, localizarse. Para la autora, la preeminencia de la mirada en el discurso médico permitió una nueva conceptualización de la enfermedad porque sustituyó al síntoma: "El saber médico es pasivo frente al síntoma, ahí donde éste habla, aquél calla; esto hace del médico alguien en permanente espera. El signo, por el contrario, es producto de la actividad del médico, ahí no hay espera, sino localización, búsqueda activa, incluso, creación" (Bacarlett, 2010: 130).
} 
primeros planteamientos que surgieron a raíz del invento de M. Daguerre. La aparición de la cámara oscura implicó una revolución respecto a las teorías científicas sobre la luz y la óptica por su capacidad de reproducir fielmente la realidad mediante imágenes capturadas por la luz: "La fidelidad con la que el daguerrotipo reproducía la realidad respondía a un nuevo concepto de «verdad», la científica y objetiva, alejada de la verdad artística de los lápices y pinceles del artista" (López, 2006: 103). La fotografía, entonces, fue concebida como un mero auxiliar de la ciencia que reproducía imágenes-documento que daban cuenta de la realidad objetivamente. Por lo tanto, la figura del operator, en términos bartheanos, fue despojada de cualquier sensibilidad artística, y su función se circunscribía a la manipulación de la cámara. No obstante, la fotografía no pudo deslindarse de su referente más inmediato, la pintura, por lo que surgieron cuestionamientos sobre la posibilidad de que un medio industrial irrumpiera en la esfera del arte, desplazando la mirada y la percepción, elementos constitutivos del hombre, al ojo mecánico de una cámara.

La precariedad económica y la imposibilidad de subsistir del arte provocan que el padre del narrador abandone sus pretensiones artísticas para incursionar en una actividad en la que se pone en juego, no las habilidades del hombre que manipula la cámara, sino el valor utilitario de los objetos que produce: imágenes que testimonian, de manera fidedigna y objetiva, la realidad de los cuerpos anómalos intervenidos por el escalpelo del doctor Ruellan, pero que no tienen un valor estético inherente desde la perspectiva del narrador. De esta manera, la fotografía se presenta, en la actividad del padre, desprovista de su función artística (como originalmente surgió en el siglo XIX), y el operator como una prolongación mecánica de la cámara fotográfica. De ahí que el narrador califique la actividad de su padre como un empleo parasitario, ya que subsiste no por sus propios medios, sino que depende y se beneficia del cuerpo anómalo que fotografía. El trabajo de fotógrafo especializado en oftalmología que desempeña el padre del protagonista consiste en tomar dos series de fotografías a los pacientes del doctor Ruellan, antes de la cirugía y después de esta, pero en ocasiones sucede que "el doctor comete alguna falla — nadie, ni siquiera él, es perfecto - entonces la persona se vuelve a presentar para que le tomemos una nueva serie por la cual pagará otros trescientos euros" (Nettel, 2008:14). Cancelada la valoración artística de las imágenes que captura la máquina, solo resta otro tipo de valoración que se traduce en términos económicos, acentuando todavía más la función meramente utilitaria de la fotografía.

La actividad médica del doctor Ruellan puede considerarse también como parasitaria porque se beneficia, de la misma manera que el padre del protagonista, del cuerpo anómalo de sus pacientes y, sobre todo, de la necesidad de estos por mejorar estéticamente sus ojos. A propósito, el narrador apunta que:

a pesar de lo que pudiera pensarse, la cirugía de los párpados son muy frecuentes y sus razones innumerables, comenzando por los estragos de la edad, la vanidad de la gente que no soporta las marcas de la vejez en el rostro; pero también los accidentes de coche, que a menudo desfiguran a los pasajeros, las explosiones, los incendios y otra serie de imprevistos. (Nettel, 2008: 14)

La búsqueda de la belleza de esos cuerpos contrariados por la vejez y la desfiguración, percibidos como una desviación de los principios armónicos del cuerpo sano, encuentra respuesta 
en la práctica médica, que funciona como un medio que restaura y reinstala el cuerpo dentro de la norma que este desvía; convierte la excepción en la regla, lo ilegal, en lo legal. En ese sentido, el escalpelo del doctor Ruellan cancela la posibilidad de que la anomalía sea otra manifestación posible y aceptable de la vida, devolviendo cuerpos en apariencia sanos, pero completamente indiferenciados entre sí. Por lo menos así lo percibe el narrador, quien después de mirar los diversos rostros que el doctor ha modificado, encuentra en ellos un rasgo abominable: "de algún modo, todos ellos se parecen. Es como si el doctor Ruellan imprimiera una marca distintiva en sus pacientes, un sello tenue, pero inconfundible" (Nettel, 2008: 17). Desde la perspectiva del narrador, lo abominable, lo monstruoso habita no en la deformación de los párpados que confiere singularidad al cuerpo, sino en la corporalidad uniforme, sin identidad. Es en esa deformación, en ese "gesto", que el narrador encuentra un valor profundo y fascinante: la belleza. En el texto hay una permanente tensión entre el concepto de belleza del narrador y el que se infiere de la práctica médica; esta tensión, me parece, trasluce la visión de mundo de Guadalupe Nettel.

El siglo XXI se caracteriza por una constante desnaturalización del cuerpo mediante prácticas publicitarias y médicas que responden, como un paliativo, al miedo atávico que la sociedad experimenta ante la muerte y la anormalidad. Estas prácticas proyectan y promueven un ideal de belleza estándar, impersonal y homogéneo que, de inmediato, le niega cualquier otra posibilidad al cuerpo. El concepto de lo bello netteliano se sitúa de lado opuesto a las prácticas contemporáneas que regulan y controlan el cuerpo, eliminando u ocultando cualquier rasgo que implique una desviación de la norma. En contraposición, la escritura de Nettel visibiliza aquello que la medicina y la publicidad intentan ocultar; por tal motivo el narrador se refiere a los párpados de esta manera: "la piel del párpado es una delicadeza insospechada" (Nettel, 2008: 14), "esa parte del cuerpo que he visto desde la infancia, y por la que jamás he sentido un atisbo de hartazgo, me resulta fascinante" (Nettel, 2008: 15).

Esta atracción instaura al narrador, como la anomalía, fuera de la norma, constituyéndolo como un personaje límite; pero más allá de la configuración de este, me interesa destacar el vínculo que acerca su fascinación a la propia sensibilidad artística de la autora, quien sostiene que la materia prima de su literatura es visibilizar "las cosas que la gente prefiere no mirar" (Martínez, 2014), de la misma manera que el narrador visibiliza la anomalía como un posibilidad, incluso, artística.

Las paredes del negocio familiar, "cercano a la place Gambetta" (Nettel, 2008: 14) son testigos silenciosos de la veta artística del padre del narrador, pues en ellas cuelgan una serie de fotos que tomó en su juventud: "un puente medieval, una gitana tendiendo ropa junto a su remolque o una escultura expuesta en el jardín de Luxemburgo, con la que ganó un premio juvenil en la ciudad de Rennes. Basta verlas para saber que, en una época muy lejana, el viejo tenía talento" (Nettel, 2008: 14). Aunque las imágenes revelan las pretensiones artísticas del padre del protagonista, estas no generan en él una honda impresión, pues las considera nada más que retratos de una realidad objetiva con un valor documental: escenas de la vida cotidiana y paisajes arquitectónicos. Sin embargo, no sucede lo mismo con la fotografía de un niño muerto en el quirófano del doctor Ruellan: "Mi padre también conserva en sus paredes obras de factura más reciente: el rostro de un niño muy bello que murió en el quirófano del doctor Ruellan (un 
problema de anestesia), cuyo cuerpo resplandece en la mesa de operaciones, bañado por una luz muy clara, casi celestial, que entra de manera oblicua por una de las ventanas" (Nettel, 2008: 15).

La foto que observa con atención el narrador no puede dejar de vincularse con una práctica fotográfica muy concurrida en el siglo XIX, el retrato post mortem. En esta práctica, los esfuerzos del fotógrafo se centraban, meramente, en un montaje, es decir, en la manipulación del objeto para que la materia inerte cobrara vida en la imagen capturada por la máquina.

La morbidez que acompaña la fotografía que cuelga en las paredes del estudio es trascendida por la mirada del narrador, quien encuentra en la luz que se filtra por la ventana el elemento, involuntario y azaroso, que otorga belleza a la imagen. El efecto que produce la imagen en el ánimo del narrador puede explicarse desde los planteamientos teóricos de Roland Barthes, para quien el quid de la imagen fotográfica es la de visibilizar "el detalle", el punctum, el objeto parcial que atrae, que despunta y lastima, porque en él se concentra el valor estético de la imagen (Barthes, 1989: 59). En el cuento, el valor artístico de la fotografía no es una cualidad inherente a la imagen ni producto de las capacidades artísticas del operator, sino, más bien, está dada por la mirada del narrador, en su calidad de spectator, es decir, el sujeto que la contempla, porque este es capaz de percibir el punctum de la imagen fotográfica. La sensibilidad perceptiva del narrador, ese modo particular de mirar el "detalle" que confiere el estatuto artístico a una imagen, desatará su obsesión por capturar y preservar el "gesto" que lo fascina y perturba, acción que solo es posible mediante el ojo mecánico de la cámara fotográfica.

El narrador interrumpe la descripción de las fotos que cuelgan en las paredes para hablar sobre su trabajo como ayudante en el estudio fotográfico de su padre. Aunque el narrador aprendió, desde muy joven, el oficio de fotógrafo médico especializado en oftalmología, su función se limita a labores de oficina, en concreto a la contabilidad del negocio familiar. A pesar de la actividad mecanizada que realiza, el narrador no puede negar un impulso que, de vez en cuando, lo acompaña en sus caminatas solitarias por las calles de París. En este momento de la narración confluyen, coherentemente, los dos discursos que sustentan el cuento: el discurso sobre el cuerpo y el de la fotografía. Esta articulación discursiva promueve la imagen del artista enfrentado al revelamiento del objeto estético:

Cuando paseo, generalmente lo hago sin la cámara, ya sea porque se me olvida o por miedo a perderla. Confieso sin embargo que a menudo, mientras camino por la calle o por los pasillos de algún edificio, siento deseos repentinos de tomar una foto, no de paisajes o puentes como hizo alguna vez mi viejo, sino de párpados insólitos que de cuando en cuando detecto entre la multitud. (Nettel, 2008: 15)

Los largos paseos en solitario que realiza el narrador por las calles de París sin un propósito específico son un guiño que lo vincula con la imagen del flâneur, quien indolente mira el paisaje de la ciudad, pues esta no le revela ningún sentido. A propósito de la obra de Walter Benjamin, Pilar Carrera apunta que:

El flâneur no es un bohemio ni posee en su disposición la justificación del sabio en actitud contemplativa. [...] No extraer utilidad alguna de los objetos que encuentra en su camino equivale a dejarlos permanecer en ese estado de gracia en el que se representa la aparente ausencia de 
sentido, equivale a privarlos de todo porqué, a convertirlos en una mera palabra. (Carrera, 2004: 44)

La actitud indiferente que el narrador demuestra por el paisaje parisino se traduce en su desinterés por llevar consigo la cámara en sus andanzas por la ciudad porque no hay nada en ella que inspire a "su veleidoso lente" (Nettel, 2008: 17), metáfora del caprichoso e inconstante ingenio del personaje que solo se manifiesta cuando se revela el objeto de su obsesión, el objeto artístico que da sentido a su ejercicio como fotógrafo, es decir, como artista: los párpados anómalos. En sus paseos esporádicos por la metrópolis, de pronto, se genera en él un deseo por fotografiar no paisajes y esculturas, como alguna vez hizo su padre, sino párpado insólitos. De la multitud uniforme e indiferenciada, emerge, de manera imprevista, el "gesto" en el que radican sus obsesiones, que a fuerza de ver cotidianamente, adquiere un sentido familiar y fascinante para el narrador. La sensibilidad perceptiva del personaje se desplaza hacia aquello "que la gente prefiere no mirar" (Martínez, 2014): la anomalía de los cuerpos posee un significado misterioso y oculto, que el narrador intenta capturar en la imagen fotográfica: "Esa parte del cuerpo [...] exhibida y oculta de manera intermitente, obliga a permanecer alerta para descubrir algo que de verdad valga la pena" (Nettel, 2008: 15-16).

$\mathrm{Si}$, como lo apunté al inicio, la anomalía instaura la particularidad del cuerpo que la contiene, es esta misma, trasladada a la fotografía, la que otorgará la distinción artística a la imagen porque funcionará como el punctum bartheano, el "gesto" oculto que se revela singular y único ante la mirada sensible de un narrador que es capaz de ver la belleza en la deformación. Es ese "gesto" el que provoca e impulsa el ingenio del artista, quien, en una suerte de poética, define los principios que rigen su labor fotográfica:

El fotógrafo debe evitar parpadear al mismo tiempo que el sujeto de estudio y capturar el momento en el que el ojo se cierra como una ostra juguetona. He llegado a creer que para eso se necesita una intuición especial, como la de un cazador de insectos, no creo que haya mucha diferencia entre un aleteo y un batir de pestañas. (Nettel, 2008: 16)

El narrador reinstaura la dimensión humana en el ejercicio fotográfico, en contraposición a la actividad mecanizada de su padre. El cuerpo de operator ya no será una prolongación del ojo mecánico de la cámara, sino una mediación entre su mirada y el objeto artístico que estará al servicio de su ingenio. No debe pasar desapercibido el lenguaje poético que emplea la autora para construir imágenes que vinculan, por un lado, la figura del fotógrafo con la del cazador, aquel que acecha y captura; por otro, el movimiento de los ojos con el aleteo de los insectos.

El valor poético de esta imagen radica no solo en la comparación de la fragilidad de la materia con la que están constituidos tanto la piel de los ojos como las alas de los insectos, sino también en la revelación de ese modo particular de mirar del narrador que le permite capturar en una imagen el instante preciso en el que se revela la belleza del "aleteo de los ojos".

La manera de construir la mirada en el texto no puede dejar de vincularse con las declaraciones de Nettel sobre los principios que rigen su escritura que, me parece, se filtran en la conceptualización que el narrador realiza sobre su actividad como fotógrafo. El narrador encuentra que en el pliegue de los párpados habita un misterio insospechado que se descubre de 
manera intermitente cada vez que el ojo sano parpadea, por lo cual el fotógrafo debe permanecer atento para capturar en una imagen el instante de esta revelación. Cada vez que el ojo "aletea", como las alas de los insectos, descubre de manera fugaz ese misterio insospechado, por lo tanto, la condición de los párpados caídos expondrá permanentemente el misterio que obsesiona al narrador, y de ahí su fascinación por esta condición física. Si los párpados caídos representan la transparencia constante del misterio, es este mismo gesto el que la autora busca visibilizar y fijar mediante la palabra escrita. Ese modo particular de mirar la realidad, de hacer visible "aquello que la gente no quiere mirar" revela la sensibilidad artística de la autora y el modo de articular su lugar en el mundo.

\section{Poseer el objeto artístico}

La mirada se identifica tradicionalmente con el saber y el conocimiento porque es a través de esta que asimilamos la realidad, pero también está relacionada con el deseo de poseer (Cirlot, 2013: 314). Si la cámara fotográfica ayuda al narrador a capturar el "gesto" de los cuerpos anómalos con la intención de preservarlo en una imagen, el encuentro erótico, en sustitución de la cámara, permitirá al narrador poseer materialmente el objeto de sus obsesiones, aunque solo sea en la fugacidad de un instante.

Las calles de París, por su carácter de espacio abierto y público, no son el lugar idóneo para que la obsesión del protagonista se proyecte porque expondrían su secreto, el gusto por la anomalía, ante la mirada de los demás. Es por esta razón que el personaje encuentra en la intimidad del negocio familiar el reducto en el que vuelve posible su búsqueda por capturar la belleza de los párpados anómalos. Sin embargo, su práctica fotográfica implica, de acuerdo con el narrador, dos inconvenientes: por un lado, lo enfrenta con la marca "abominable" que el doctor Ruellan imprime a todos los cuerpos que interviene y, por otro, le genera un paulatino desinterés ver, constantemente, párpados "casi todos horribles" (Nettel, 2008: 17). El artista parece enfrentarse a un impasse con su objeto artístico, pues ya no percibe en él ese punctum que lo perturba y mueve. Si la uniformidad de los rostros intervenidos por el escalpelo provoca aversión en el narrador, la repetición incesante de párpados caídos le produce también una cierta indolencia. Parece, como ya lo mencioné, que la verdadera búsqueda del artista reside en la singularidad de los cuerpos, en el "gesto", lo único e irrepetible, que expone la diferencia entre un cuerpo y otro. El genio "veleidoso" del artista se moviliza solo ante la presencia de lo memorable y de lo excepcional: "Recuerdo haber visto pocos casos verdaderamente notables en nuestro establecimiento. Cuando esto ocurre, me acerco a mi padre que prepara la película en la trastienda, y le pido al oído que me deje disparar el obturador. Él siempre accede, aunque sin entender la razón de mi súbito interés" (Nettel, 2008: 17). La manía del narrador se convierte en el secreto, nunca revelado, que define su ejercicio como fotógrafo y que, de alguna manera, lo caracteriza como un ser aislado, cuyas acciones son incomprensibles para su padre.

La narración lineal se interrumpe con la incursión de un recuerdo que sirve al protagonista para rememorar uno de los casos excepcionales de párpados caídos, a partir del cual se va tejiendo una historia amorosa que concentra la búsqueda final del narrador- artista: poseer 
materialmente el objeto de su obsesión, el objeto estético. Un día de noviembre de intenso frío parisino, se presenta en el estudio una paciente que el narrador debe fotografiar en ausencia de su padre. A pesar del malestar que le provoca la parsimonia y la actitud tímida de la joven, de inmediato, el narrador se siente atraído y afectado por su belleza:

Su párpado izquierdo estaba unos tres milímetros más cerrado que el derecho. Ambos tenían una mirada soñadora, pero el izquierdo demostraba una sensualidad anormal, parecía pesarle. Al mirarla me embargó una sensación curiosa, una suerte de inferioridad placentera que suelo experimentar frente a las mujeres excesivamente bellas. (Nettel, 2008: 18).

El narrador no ofrece ninguna descripción que nos permita reconstruir la belleza de esta mujer porque su mirada se centra solo en su anomalía en la que descubre un nuevo valor: el sensual. En ese sentido, se puede inferir que la belleza de la mujer radica en su condición física, cuyo valor solo es perceptible para la mirada del narrador, que experimenta una fuerte atracción física por la joven, pero también una especie de enamoramiento.

La comunicación entre el narrador y la mujer es insustancial: solo sabemos que es originaria de Picardía y que espera regresar pronto a Pontoise después de la cirugía para no perder el año escolar. La timidez de la chica, esa sensación que se produce cuando nos sabemos observados, exaspera al narrador, quien, sin embargo, apunta que: "hubiera dado cualquier cosa por seguir mirando durante la tarde entera ese párpado pesado y al mismo tiempo frágil y habría dado el doble porque esos ojos se fijaran en mí" (Nettel, 2008: 19). Si la sensibilidad artística del narrador se concentra es su capacidad de mirar y descubrir la singularidad y la belleza en la deformación, el deseo de convertirse en el sujeto que es observado entraña su aspiración por ser reconocido también en su particularidad.

Frente a esa mirada que lo perturba, el narrador experimenta una suerte de vaivén emocional que va desde el deleite por la belleza de la mujer, la empatía por su ingenuidad, la desesperación por su actitud tímida, hasta el enojo y la depresión cuando la joven le confiesa que vive en Pontoise y que no tiene intención de radicar en París: "La idea de que esa mujer viviera en otra ciudad bastó para deprimirme. Empecé a sentirme malhumorado. De manera repentina, quizás un poco brusca, interrumpí la charla para ir a buscar la película [...]. Nunca en mi vida profesional había sido tan poco amable" (Nettel, 2008: 19). La idea de perder el cuerpo que contiene ese "gesto" afecta profundamente al narrador que, en un intento desesperado, manipula a la mujer para que desista de operarse: “-No sé si usted esté enterada - le dije simulando compasión-, los resultados nunca son perfectos. Su ojo no será igual al otro. ¿Se lo ha explicado el doctor?" (Nettel, 2008: 19).

La actitud indiferente de la mujer respecto a la cirugía y a sus resultados es lo que en realidad desespera al narrador. Este quiere hacerla desistir y, como último recurso para lograrlo, siente el deseo de explicarle el rasgo abominable que él encuentra en los pacientes del doctor Ruellan después de la cirugía, pero renuncia a su intento porque supondría exponer su manía, su secreto: "Pensé en decirle que, de cualquier manera, quedaría con el sello inconfundible de los pacientes operados por el doctor Ruellan, esa tribu de mutantes. Sin embargo, no tuve el valor necesario" (Nettel, 2008: 20). Como ya lo apunté, el carácter perturbador, desde la perspectiva 
del narrador, no radica en la anomalía de los ojos, sino, más bien, en su uniformidad después de la operación. Si lo que está fuera de la norma atrae al narrador, lo que está dentro de esta le produce un completo rechazo porque implica la mutilación de ese "gesto" que le otorga identidad a los cuerpos. Me parece un guiño interesante que el narrador emplee el sustantivo "mutante" para referirse a los pacientes del doctor Ruellan porque, en consonancia con el discurso médico, el mutante es aquel organismo que ha sido alterado y que ha perdido su forma natural; modificación que realiza el escalpelo del doctor Ruellan en el cuerpo de sus pacientes con la finalidad de "embellecerlos", es decir, reinstaurarlos dentro de la norma.

Los intentos fallidos del narrador por cambiar la opinión de la joven provocan en él la resolución del artista: capturar, mediante el ojo de la cámara, el instante en el que se revela la belleza de su objeto estético en un intento por preservarlo: "En lugar de las tres tomas habituales disparé el obturador quince veces más y habría seguido así hasta el anochecer si mi padre no hubiera llegado" (Nettel, 2008: 20).

Después de ese encuentro fugaz, el narrador cae en un abatimiento que no es mitigado por las imágenes de la joven porque estas son el recordatorio permanente de la voluptuosidad que encuentra en los ojos de esta mujer. Sin embargo, el sufrimiento cede su lugar al temor de un reencuentro: "Durante tres meses esperé con auténtico terror a que viniera por la segunda serie, de ningún modo quería estar presente. Cada lunes echaba un vistazo a la agenda de mi padre para saber en qué momento ausentarme. Pero ella nunca vino" (Nettel, 2008: 21). Como se advierte, el narrador es afectado emocionalmente no por la mujer en sí, sino por el recuerdo, la imagen que tiene de ella, y es por esta razón que un reencuentro implicaría una distorsión de la imagen que habita en su memoria; pero su miedo radica también en enfrentarse a sus más profundos temores, la indiferenciación, la mutilación de ese "gesto" que convierte en abominables a los hombres.

Después de unos meses y transcurrido el invierno, el narrador decide salir a las calles de París en búsqueda de "algún párpado interesante" (Nettel, 2008: 21). Deambulando por los muelles del Sena, de pronto, el narrador se encuentra con la joven mujer, quien, para su sorpresa, conserva la condición original de sus ojos. Esta le explica que no se operó debido a que el doctor Ruellan había tenido un inconveniente, pero que reprogramó la cirugía, motivo por el cual se encontraba nuevamente en la ciudad. El narrador, caracterizado por su soledad, su incapacidad para mantener relaciones con otras personas y sus manías —así lo demuestran su soltería y su miedo a reencontrarse con la mujer-, la invita, sin ningún reparo, a pasar la tarde con él. Como si se tratara de la primera cita de enamorados, los dos pasan la tarde en la isla Saint-Louis comiendo helado, escuchando jazz y platicando sobre sus proyectos futuros. Las escenas de este encuentro se reúnen, en la memoria del narrador, en una sola imagen: la luz del atardecer que tiñe de naranja los párpados de la mujer, imagen que condensa toda la felicidad experimentada por el narrador: "De haber llevado la cámara tendría ahora alguna prueba, no sólo de la mujer ideal sino también del día más alegre de mi vida" (Nettel, 2008: 22). Este encuentro se prolonga hasta "una pocilga cerca de Bonne Nouvelle" (Nettel, 2008: 22), lugar en el que ambos pasan la noche.

El encuentro sexual se transforma en una suerte de ceremonia erótica alrededor de los ojos de la mujer: "Le besé los párpados una y otra vez y, cuando me cansé de hacerlo, le pedí que no cerrara los ojos para seguir disfrutando de esos tres milímetros de voluptuosidad desquiciante" 
(Nettel, 2008: 23). Por fin, el narrador puede poseer materialmente el "gesto" que lo despunta, en términos bartheanos, pero este encuentro implica también un desbordamiento, un salirse de sí mismo ante la posesión de la belleza encarnada en los ojos anómalos: "entonces sin ningún tipo de pudor o inhibiciones le rogué que no se operara, que se quedara conmigo, así, como era en ese momento" (Nettel, 2008: 23). Desnudado su secreto, el narrador no encuentra eco en la joven mujer porque no hay posibilidad de establecer una comunión verdadera con un sujeto que se encuentra cercano corporalmente, pero alejado de un mundo incomprensible para él, habitado por manías y obsesiones: "pero ella pensó que se trataba de una cursilería, una de esas mentiras exaltadas que se dicen en circunstancias como ésa” (Nettel, 2008: 23).

Todos los intentos del narrador son fallidos, así que acepta la inevitable cirugía de la mujer, no sin sentir como si hubiera perdido una batalla; la más importante. Después de múltiples promesas de amor, el narrador acompaña a la joven al pabellón preoperatorio; la última imagen filtrada por sus recuerdos es de las ojeras que surcaban los ojos cansados de la joven, las cuales le otorgaban una mayor belleza. El narrador abandona a la mujer, pero en el texto este acto que puede considerarse una completa cobardía es planteado como una derrota; la derrota del artista por intentar poseer por completo el objeto estético.

El personaje, entonces, se debate entre sus deseos y su posición como artista:

La imaginé despertando sola, en ese cuarto hostil con olor a desinfectante. Hubiera deseado poder estar ahí acompañándola y lo hubiera hecho de no haber tenido tanto en juego: mis recuerdos, mis imágenes de esos ojos que, de haberlos visto después, idénticos a los de todos los pacientes del doctor Ruellan, habrían desaparecido de mi memoria. (Nettel, 2008: 24)

Más allá de la imagen congelada que produce la cámara fotográfica, la memoria se constituye, al parecer, como el único medio capaz de preservar la belleza y vivificar ese "gesto" diferenciador de los cuerpos, por lo que enfrentarse al cuerpo "mutilado" de la mujer después de la cirugía implicaría una distorsión, una afectación de los recuerdos que intenta conservar para sí mismo.

Finalmente, el cuento termina cuando el narrador describe la rabia que siente por el doctor Ruellan cada vez que, de manera esporádica, mira una foto de la mujer: "Al hacerlo me invade una suerte de asfixia y un odio infinito hacia nuestro benefactor, como si de alguna forma su escalpelo también me hubiera mutilado" (Nettel, 2008: 24). El encuentro sexual que sostuvo con la mujer tiene hondas repercusiones vitales en el narrador porque implicó enfrentarse con la imposibilidad de poseer la belleza permanentemente, pero también con la negación de ser reconocido y aceptado en su completa singularidad como un sujeto, también, anómalo. De manera simbólica, el escalpelo del doctor Ruellan interviene en él, regresándolo, después de enfrentarse a este reconocimiento, como un ser derrotado. La mutilación elimina su propia anomalía, lo restaura en la norma que desvía, lo convierte en un ser indiferenciado, pues niega la posibilidad de que su manía sea una expresión coherente y aceptable de la realidad. Esta derrota, de la que habla el narrador, se concentra en sus últimas declaraciones: "No he vuelto a salir con la cámara desde entonces, los muelles del Sena no me prometen ya ningún misterio" (Nettel, 2008: 24). 
La derrota del narrador no es, por ningún motivo, extensiva a la autora, pues toda su obra es una comprobación de la búsqueda permanente por capturar y visibilizar permanentemente el misterio que habita en ese "gesto" que particulariza a los individuos. Si el develamiento de ese misterio se concentra en los cuerpos anómalos, se infiere que la sensibilidad artística de Guadalupe Nettel apunta a la construcción de realidades posibles y aceptables del cuerpo que articulan un modo de mirar y, sobre todo, de posicionarse en el mundo. "Ptosis", en este sentido, es un espacio de articulación de los principios rectores de la escritura de Nettel y de reflexión sobre su quehacer literario. Si, como escribe Ortega y Gasset, en los límites de la realidad radica lo bello, es ahí donde Guadalupe Nettel desplaza su mirada y su sensibilidad artística para develar la belleza de cuerpos, cuya realidad ha sido rechazada por las prácticas que encumbran cuerpos indiferenciados y homogeneizados, y mutilan, desde la perspectiva de la autora, la singularidad del individuo. El develamiento de esa belleza no será, como en el caso del cuento, capturado por el ojo mecánico de una máquina, sino mediante la palabra escrita que visibilizará permanentemente el misterio que habita en los párpados caídos.

\section{Bibliografía}

BACARLETT PÉREZ, María Luisa (2010): Filosofía y enfermedad. Una introducción a la obra de Georges Ganguilhem. México, Universidad Autónoma del Estado de México - Miguel Ángel Porrúa.

CARRERA, Pilar: Walter Benjamin: el paseante $y$ la ciudad, https://addi.ehu.es/bitstream/10810/4944/1/TESIS-CARRERA.pdf, 04/09/2016.

FRIERA, Silvina: "Entrevista a Guadalupe Nettel", Página 12, http://www.pagina12.com.ar/diario/suplementos/espectaculos/4-9534-2008-03-18.html, 04/09/2016.

LÓPEZ SUÁREZ, Mercedes: "Fragmentos de una reflexión sobre literatura y fotografía", Cuadernos de Filología Italiana, 13 (2006), 97-118.

MARCOS, Ana: "Entrevista a Guadalupe Nettel”, El País, http://cultura.elpais.com/cultura/2013/06/07/actualidad/1370607912_129392.html, 04/09/2016.

MARTÍNEZ AHRENS, Jan: "Entrevista a Guadalupe Nettel”, El País, http://cultura.elpais.com/cultura/2014/12/04/babelia/1417700666_856424.html, 04/09/2016.

NETTEL, Guadalupe (2008): Pétalos y otras historia incómodas. México, Anagrama. 
(C) Jazmín G. Tapia Vázquez

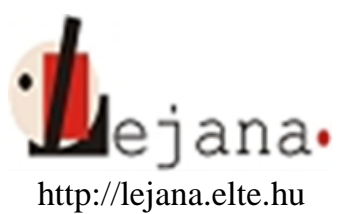

Universidad Eötvös Loránd, Departamento de Español, 1088 Budapest, Múzeum krt. 4/C

Recibido: 06 de junio de 2016

Aceptado: 09 de julio de 2016 